\title{
Remarks on Ernesto Bozzano's La Psiche Domina la Materia
}

\author{
Carlos S. Alvarado, Ph.D. \\ University of Virginia
}

\begin{abstract}
Modern discussions of physical phenomena around the time of someone's death have not mentioned Italian psychical researcher Ernesto Bozzano's last study on the subject, La Psiche Domina la Materia (1948). Posthumously published, the book included an analysis of cases of falling pictures, disturbances of clocks, and a variety of other effects such as bell ringings, breakage and movement of objects, all connected by experiencers to death. In addition to reminding us that such reports of physical manifestations exist, Bozzano inspires us with ideas for further research. His book, however, suffered from several problems, among them a dogmatic approach to the interpretation of the cases, and the use of cases lacking relevant information.
\end{abstract}

KEY WORDS: Ernesto Bozzano; death-related physical phenomena; falling pictures; stopping clocks; movement of objects.

While several writers have discussed physical phenomena coinciding with death (Alvarado, 2006b; Rhine, 1963; Roll, 1986; Wright, 2002) and the work of Italian psychical researcher Ernesto Bozzano (1862-1943) on this subject (Alvarado, 2005; Ravaldini, 1993), Bozzano's last publication on the topic has been neglected by modern researchers. I am referring to La Psiche Domina la Materia: Dei Fenomeni di Telekinesia in Rapporto con Eventi di Morte [The Psyche Rules Matter: The Phenomena of Telekinesis in Relation to Death

Carlos S. Alvarado, Ph.D., is Assistant Professor of Research in the Department of Psychiatry and Neurobehavioral Sciences at the University of Virginia. The author thanks Nancy L. Zingrone, Ph.D., for useful editorial suggestions for the improvement of this paper. Reprint requests should be addressed to Dr. Alvarado at the Division of Perceptual Studies, Department of Psychiatry and Neurobehavioral Sciences, Box 800152, University of Virginia Health System, Charlottesville, VA 22908; email: csa3m@virginia.edu. 
Events], published in 1948. In this brief note I will summarize the contents of this work with the intent to familiarize contemporary students of near-death phenomena with this forgotten work.

\section{Summary of the Book}

The book was a revision of previous publications (Bozzano, 19211922, 1923). During World War II, Bozzano revised his original writings on death-related telekinesis, as well as some of his monographs on other topics, adding many new cases. The monograph was published posthumously by Gastone De Boni (1908-1986), who considered himself Bozzano's disciple and who inherited Bozzano's books, unpublished manuscripts, and surviving correspondence (Ravaldini, 2006). After Bozzano's death in 1943, De Boni brought the unpublished revised editions of the monographs to print.

La Psiche Domina la Materia had 119 pages of text and included a list of the cases and researchers cited in the monograph that De Boni prepared (pp. 121-123). In addition to an introduction and a conclusion, the book had three chapters about physical phenomena presumably related to the death of an individual known to the perceiver. The chapters covered falling pictures, clocks that stopped or were affected in other ways, ringing bells, breaking and movement of objects, and various other physical manifestations.

The book included 114 numbered cases taken mainly from the spiritualist and psychical research literatures. However, only 56 were presented in detail. The rest appeared in a list that identified the effect observed and the bibliographical source in two or three lines. The cases came from publications in different languages. For example, the chapter about clocks included 13 detailed cases, eight published in English, four in French, and one in German.

While most cases coincided with death, there were a few that anticipated or followed death. An example of the latter was taken from the Proceedings of the Society for Psychical Research. It was reported by W. E. Ward, who was having a conversation with a doctor, Anna Lukens, at her office. They were talking about their common friend, referred to as "Professor Cope," who had died some time before. While neither Ward nor Lukens thought the case was impressive, Bozzano clearly thought so. As Ward wrote in the original report: 
I was referring to Cope's interest in psychical matters, and saying how satisfactory it would be if we could get some reliable report from him of his impressions of the real life he has so lately entered into. And immediately the Doctor's large musical box commenced playing, and continued to play for over five minutes, to our great and almost bewildering astonishment, and ceased playing only when I commenced trying to account for such an unexpected entertainment through ordinary natural methods. Just as soon as I remarked how it might be accounted for, it stopped as abruptly as it began.

The instrument had not been wound up in over three months, and when last used, if there had remained unused any tension of the spring, it might have been released long before by the jarring it had been subject to through the occasional shifting of the furniture in the room....

A curious part of the experience ... was the response I received to a mental question I asked some ten or fifteen minutes after the playing ceased. The question was addressed to Professor Cope in about this form, "Edward, are we indebted to you for the music we have just heard?" and immediately a response of three loud raps came on the floor apparently quite near me, but this was after Dr. Lukens had left the room, so is unsupported by another witness (Johnson, 1899 , p. 233).

Other cases cited were from secondhand testimony. The following is an example that I took from the English translation of a French work cited by Bozzano. The case was sent to French astronomer Camille Flammarion (1842-1925) by a woman living in Naples and involved an experience of her aunt referring to the aunt's husband who was at war:

The morning of February $12^{\text {th }}$ my aunt went into her room, about half-past ten, to look for something. At the exact moment when she stepped over the threshold of the door the portrait of her husband ... detached itself from the wall, fell, and slid over the floor to her feet. When the nail and the cord which had held up the frame were examined, they were found to be intact .... Toward the beginning of March she learned that my uncle ... had died ... from a bullet that struck him in the head, the morning of February $12^{\text {th }}$, about half-past ten. (Flammarion, 1921/1922, p. 305)

Bozzano argued that the most frequently reported effects were falling pictures, followed by clock manifestations and bell ringings. But he also pointed out that there were a great variety of effects, such as breakage and movement of objects. Many cases involved great distances between the dying persons and the witnesses of the physical phenomena. Distant telekinesis, he argued, showed the "existence of a directing will" (p. 10). 
Using his inimitable style to argue a point, Bozzano presented his views as evident conclusions that could not be doubted. For example, he declared his complete conviction that the falling of pictures could not be explained by such normal causes as the breaking of the strings holding them, a certainty most critical readers may not share. He also believed that coincidence was "definitively eliminated" (p. 117) due to the accumulation of many cases. Although the accumulation of cases may convince many that a real phenomenon exists, it is no assurance that other explanations can be confidently rejected.

Bozzano felt discarnate agency explained the physical effects in most cases. At the end of the book he referred to the "incontestable validity of the spiritualist interpretation of the phenomena of 'telekinesis in relation to death events"' (p. 117). While Bozzano believed that the great majority of cases indicated a physical effect, that is, a real movement or breakage of objects, he believed some were subjective, representing a symbolic telepathic effect. This was illustrated with a case in which three persons heard what they believed was the glass on a portrait hanging in another room breaking, a sound they heard three times in succession. However, the portrait did not in fact fall and the glass was intact. The person depicted in the portrait died about three weeks later (pp. 44-45).

Bozzano thought that a dynamic force projected from the body of the dying person could not account for the cases. He believed that such a hypothesis could not explain how specific objects were selected from among many others. This idea seemed to him incapable of scientific support due to the fact that such "vibration' is subordinated to the physical law of the inverse square of distance ... the vibrations in question cannot cross the ocean without loosing their efficacy" (p. 118). Furthermore, Bozzano pointed out that a few cases took place after a death. These were cases in which the physical effects were perceived around the time the experiencers first heard of the death, which he believed went against the dynamic hypothesis and supported instead the "logically irresistible presupposition" (p. 118) of the presence of the deceased person in the place where the effect occurred, which Bozzano felt indicated the impact of the deceased's intention to communicate. The argument, he continued, also applied to cases in which telekinesis took place when someone thought about a deceased individual, and in those 14 cases in which the physical phenomena followed the promise of the deceased to communicate after death. Bozzano did not give credence to the idea that the witnesses 
produced the phenomena through their own telekinesis, although he admitted the possibility that the phenomena could take place more rarely when the person did not die or was not close to death.

While Bozzano rejected explanations that focused on forces from the body of the dying, he did speculate about alternate concepts of force. For example, Bozzano considered the possibility that the "etheric body,' the envelope of the spirit, which just left the physical organism, remains saturated for some time with the vital fluid that allows it to be capable of acting on matter" (pp. 16-17; the topic was also discussed in Bozzano, 1934/1937). He also speculated that deceased individuals could cause physical phenomena by "taking out force and fluid from living persons" (p. 82) in the surroundings. This process, Bozzano postulated, was similar to physical mediumship in which the "mediumistic personality takes force and fluid from all the experimenters" (p. 82). Such ideas of bodily forces and subtle bodies were of course not new with Bozzano, having a long history preceding the book we are discussing (Alvarado, 2005, 2006a).

\section{Concluding Remarks}

Like other forgotten classics dealing with psychic phenomena and death, La Psiche Domina la Materia deserves to be better known by modern students of the subject. Bozzano's compilation of cases complemented more recent discussions of death-related physical phenomena (Piccinini and Rinaldi, 1990; Wright, 2002).

Nonetheless, Bozzano's approach was problematic for contemporary scientific researchers. By today research standards he was much too dogmatic about his own conclusions. Many of his interpretations were not necessarily evident from the facts, and they remain today, as in Bozzano's days, as interpretations of the evidence. Furthermore, reliance on published cases, characteristic of the case collection approach, presented several methodological problems (Alvarado, 1992). Some of the cases, such as those included in Flammarion's (1921/1922) collection, depended on the testimony of a single individual and were not very detailed. While bringing together cases collected by others can be helpful, we need to remember that because the cases have been collected by different individuals and with different purposes in mind, they often lack important information. The missing information was not limited to evidential details, but it also extended to phenomenological features and other general contextual 
information, such as the witnesses' history of psychic experiences and their beliefs.

On the positive side, Bozzano's book illustrated the variety and complexity of the phenomena and suggested directions for further research. For example, Bozzano's emphasis on the importance of death, or closeness to death, could be studied with new cases. We may ask if reports of physical phenomena are more frequent or phenomenologically different in death-related cases, as opposed to cases where death was not a feature. Are there differences between cases of sudden and gradual death? More generally, are there differences in the features of cases grouped on the basis of the physical effects, that is, falling pictures, clock disturbances, or movement of objects? Other variables such as distance and relationship between dying persons and witnesses could be considered, such as was done in the work of Sybo Schouten (1979; see also Piccinini and Rinaldi, 1990).

Future research could attempt to combine Bozzano's descriptive approach with contemporary quantitative analyses that explore detailed interaction of variables. In this way we may be able to combine the best of our past and current approaches to near-death phenomena.

\section{References}

Alvarado, C. S. (1992). Case collections in parapsychology. Exceptional Human Experiences, 10, 163-166.

Alvarado, C. S. (2005). Ernesto Bozzano and the phenomena of bilocation. Journal of Near-Death Studies, 23, 207-238.

Alvarado, C. S. (2006a). Human radiations: Concepts of force in mesmerism, spiritualism and psychical research. Journal of the Society for Psychical Research, 70, 138-162.

Alvarado, C. S. (2006b). Neglected near-death phenomena. Journal of Near-Death Studies, 24, 131-151.

Bozzano, E. (1921-1922). Dei fenomeni di "telekinesia" in rapporto con eventi di morte. Luce e Ombra, 21, 225-233, 270-276, 304-315, 375-380; 22, 13-25.

Bozzano, E. (1923). Phénomènes psychiques au moment de la mort (Psychic phenomena at the moment of death]. Paris, France: Éditions de la B.P.S.

Bozzano, E. (1937). Les phénomènes de bilocation [The phenomena of bilocation] (G. Gobron, trans.). Paris, France: Jean Meyer. (Original work published 1934)

Bozzano, E. (1948). La psiche domina la materia: Dei fenomeni di telekinesia in rapporto con eventi di morte [The psyche rules matter: The phenomena of telekinesis in relation to death events]. Verona, Italy: Europa.

Flammarion, C. (1922). Death and its mystery: At the moment of death (L. Carroll, trans.). New York, NY: Century. (Original work published 1921)

Johnson, A. (1899). Coincidences. Proceedings of the Society for Psychical Research, 14, 158-330. 
Piccinini, G., and Rinaldi, G. M. (1990). I fantasmi dei morenti: Inchiesta su una credenza [Phantasms of the dying: Survey of a belief]. Viareggio, Italy: Il Cardo.

Ravaldini, S. (1993). Ernesto Bozzano e la ricerca psichica: Vita e opere di un pioniere della parapsicologia [Ernesto Bozzano and psychical research: Life and work of a pioneer in parapsychology]. Rome, Italy: Mediterranee.

Ravaldini, S. (2006). Gastone De Boni: Una vita per la metapsichica [Gastone De Boni: A life for metapsychics]. Luce e Ombra, 106, 251-268.

Rhine, L. E. (1963). Spontaneous physical effects and the psi process. Journal of Parapsychology, 27, 84-122.

Roll, W. G. (1986). Recurrent and nonrecurrent psi effects. In K. R. Rao (Ed.), Case studies in parapsychology (pp. 46-51). Jefferson, NC: McFarland.

Schouten, S. A. (1979). Analysis of spontaneous cases as reported in "Phantasms of the Living." European Journal of Parapsychology, 2, 408-455.

Wright, S. H. (2002). When spirits come calling: The open-minded skeptic's guide to afterdeath contacts. Nevada City, CA: Blue Dolphin. 